\title{
Gordura. Questões sobre cópia e original *
}

1. É habitual começar um texto mais ou menos programático e/ou especulativo, intencional mas não abertamente vocacionado para a originalidade, com a expressão da dificuldade de definição dos conceitos que são a sua área e a sua pretensão. Este texto, fazendo-se pretensioso, coloca a questão de forma inversa. Parte de ideias vagas, da credibilidade de um senso comum de que, evidentemente, o autor julga reconhecer e fazer parte - e, portanto, não verbalizável - para uma hipotética indefinição primordial. Regride. Porque a sua ambição é anterior à comunicabilidade. Como se fosse possível recolocar o momento em que as palavras como "fotografia», "desenho» e «luz» ainda não existiam ou tivessem sido pronunciadas.

Assim, não se espere uma conclusão esclarecedora mas, pelo contrário, aceite-se um resultado muito mais surpreendente - o de ficar quase tudo na mesma, a inalterabilidade activa expressa apenas numa felicidade ou infelicidade difícil de detectar; numa satisfação ou insatisfação silenciosa sem, sequer, «se dar por isso" a não ser que estamos a ouvir ou a ler isto e, por tal, a não fazer outra coisa «em seu lugar».

(Estamos confortavelmente instalados numa posição posterior à realidade. Utilizando as palavras recorremos ao evitável subterfúgio de modelar o mundo e de recusar o que lhes escapa. Em particular, esta coisa inadmissivel - ironia minha? - de falar sobre o que dizemos e fazemos. E repare-se na consequente condenação moral do «dizer por dizer» ou do «dito por não dito»).

2. É completamente escusado e ineficaz discutir as fronteiras entre desenho e fotografia como, aliás, entre quaisquer outras coisas pela simples razão de que tal provém da nossa incapacidade de nomear (designar) estados de transição, limites elásticos e penetrantes, onde afluem configuraçðes previamente designadas/diferenciadas (Maneirismo/Barroco, Orgânico/Inorgânico, Sólido/Líquido, etc. - no fundo, tudo o que combinações binárias julgam resolver e, afinal, são apenas uma solução simplista, porque linguística, da realidade), para as quais não encontramos as qualidades/propriedades eficazes (Vivo/Não Vivo, p. ex.) ou as operaçð̄es (de medida, p. ex.) adequadas para um sempre regressado amálgama - «sentimental» - de experimentação, confrontação e transformação (artes/artesanatos/estéticas).

3. Tenho duas grandes obcessðes materiais (substanciais):

a) os colóides

b) as gorduras

Sobre os colóides e da importância de se definir o "conceito" de colagem não se trata aqui e é objecto de um texto inédito. Quanto à gordura, este texto é um indício. Nada mais. Acho que, através do estudo destas duas "substâncias», é possivel reescrever o mundo. Julgo deterem os segredos dos interstícios da natureza e da sensibilidade. Admito, no entanto, que as palavras possam vir a tornar-se inoperantes. Mas isto não deve impedir a reformulação dos conceitos com que habitualmente defrontamos a realidade.

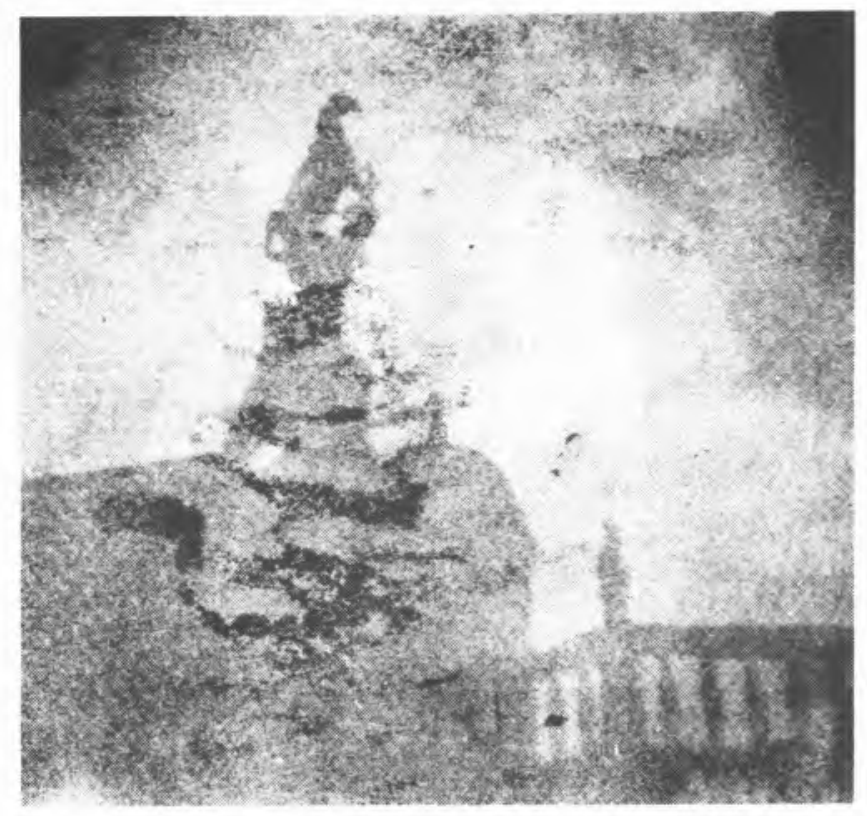

Talbot, O terraço de Lacock Abbey, calotipo, 1835

4. Gosto de desenhar, fotografar, escrever e registar sons. Apercebi-me com alguma surpresa das origens materialmente afins da fotografia, do desenho e das suas reproduçoes.

Conté inventa os «seus» lápis (1795) para resolver a falta da excelente grafite britânica que, com o Bloqueio Continental, se tinha tornado praticamente inacessivel. Utilizou uma argila e, pouco tempo depois, uma cera e uma gordura que permitiu o uso de pigmentos diversos, de menor qualidade mas mais baratos, comprimidos em cilindros no interior de outros, de madeira. Assim, mantinha-se a grande agilidade do desenho e, sobretudo, abria caminhos mais vastos, ainda hoje por desvendar, ao permitir o risco de arriscar territórios tão diferentes, dos mais inacreditáveis papéis ao inefável vidro. Os riscos e as manchas de Seurat são indissociáveis dos seus papéis.

\footnotetext{
* Este texto é uma versão desenvolvida de uma comunicação apresentada na Fundação Calouste Gulbenkian em Novembro de 1985.

a Assistente de Estética da Escola Superior de Belas-Artes de Lisboa; co-responsável pela Associaçåo Eter/Vale Tudo menos Tirar Olhos.
} 


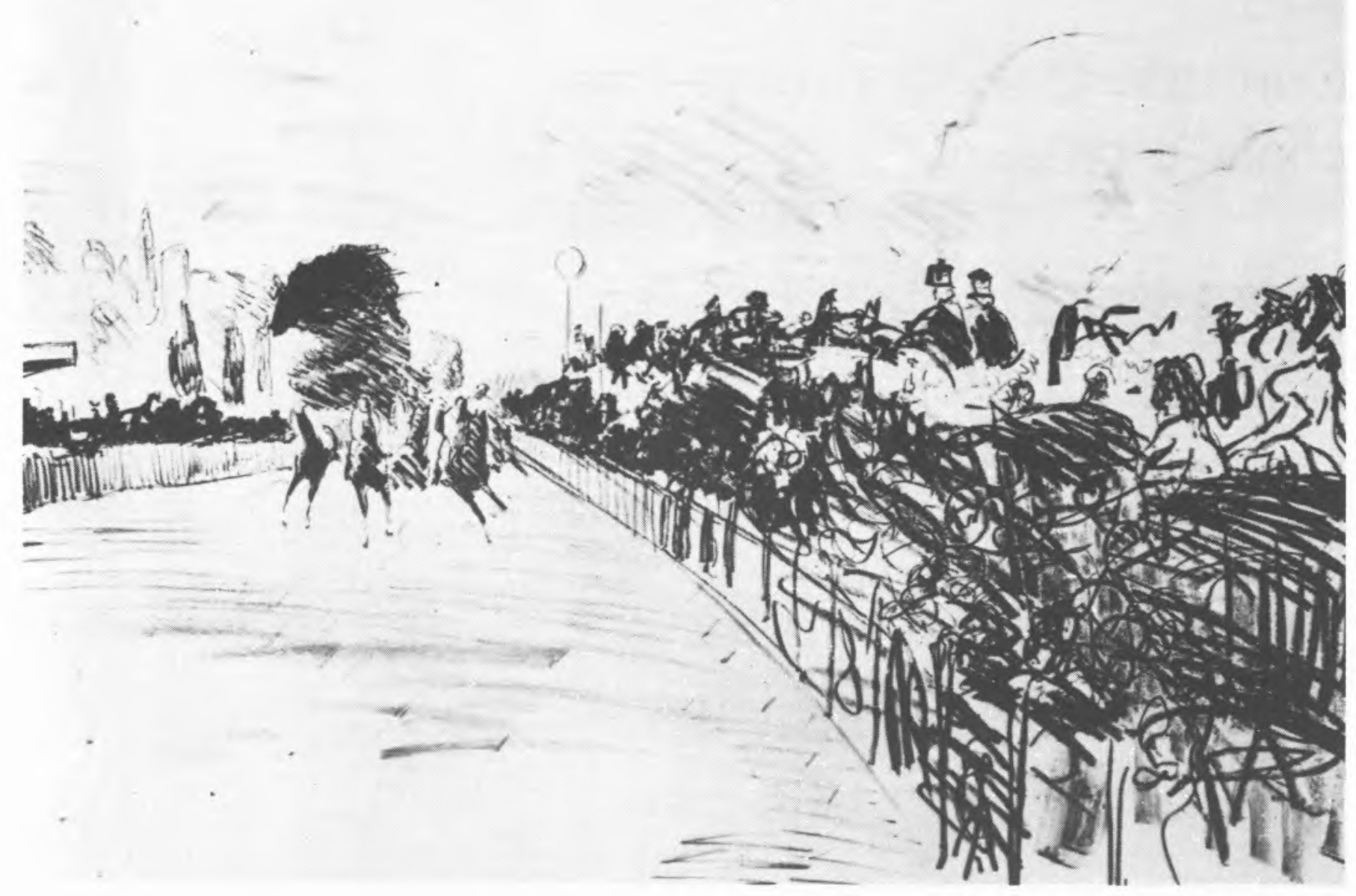

Manet, As corridas, litografia, 1864/67 (?)

Senefelder descobre e desenvolve a técnica da litografia (1798), baseada fundamentalmente numa matriz desenhada com lápis gorduroso na superfície de um calcário e possibilitando a sua transferência por combinação das propriedades da gordura e da pedra - adsorção. Assim se fazia a reprodução quase ilimitada do desenho inicial, com as suas «imperfeiçð̃es», já não corrigidas por esmerados mas entediantes gravadores, e confundindo cópia e original manual. As nuvens de Corot distinguem-se das nuvens de Millet.

Nièpce, habitual mas erradamente reconhecido como inventor da fotografia, começou por ser litógrafo e procurou na heliografia a combinação da gravura e da já conhecida câmera obscura. No entanto, pela sua ccrrespondência, crê-se que chegou a uma prova «fotográfica» (1816) em papel e a terá enviado a seu irmão Claude. Lamentavelmente extraviada, é possível que já tivesse estado, e ainda ande, nas mãos de algum de nós porque não foi devidamente fixada. De qualquer forma, Nièpce lastimava-se na carta de que o que era escuro estava claro e o que era claro estava escuro, sem ter percebido alguma vez de que tinha à sua frente o negativo fotográfico, ou seja, o referente da fotografia por excelência. Por um lado, vinha basear a tradição de que a maioria dos fotógrafos são estúpidos ou têm a vocação, também estúpida, de mártires e, por outro, deixando para a posteridade um objecto «errado" - uma heliografia que mais não é do que uma gravura betuminosa obtida com luz -, iniciava a incerteza e confusão futuras entre cópia e original real. Talbot, porque também, como Nièpce, não sabia desenhar, procurou na câmara obscura e nas propriedades fotoquímicas da prata a solução para as suas incapacidades gráficas. Não só produz um negativo (1835), também da sua janela, como o fixa. Graças ao auxílio do seu amigo astrónomo J. Herschel, começa a utilizar o hipossulfito de sódio como fixador (1839). Mas o mais interessante de tudo isto é que a gordura, outra vez, vem solucionar o problema da conversão do negativo em positivo através do seu humedecimento e consequente transparência. É, aliás, a gordura que dá uma dimensão táctil e, desde logo, estética (porque sinestésica) à fotografia. Discutem-se e escolhem-se papéis porque os positivos (calotípicos) revelam o esqueleto do negativo. Uma árvore "fotografada» é igual às suas folhas mais a textura da folha do papel sensivel.

J. Herschel é o proponente de quase todas as inovaçoes técnicas de Talbot; é, também, o enunciador original das designaçðes de "fotografia» e "positivo/negativo» $(1938 / 39)$ para aquele processo tão sedutor e, por isso mesmo, embaraçoso. A ele, apenas por razðes metodológicas, deveríamos reconhecer a paternidade conceptual fotográfica. (Quero precisar que atribuo a realização material da fotografia, na sua forma canónica, a Woodbury, 1864, por razðes que em lugar oportuno explicarei). Por várias razðes, entre as quais, o seu des- 


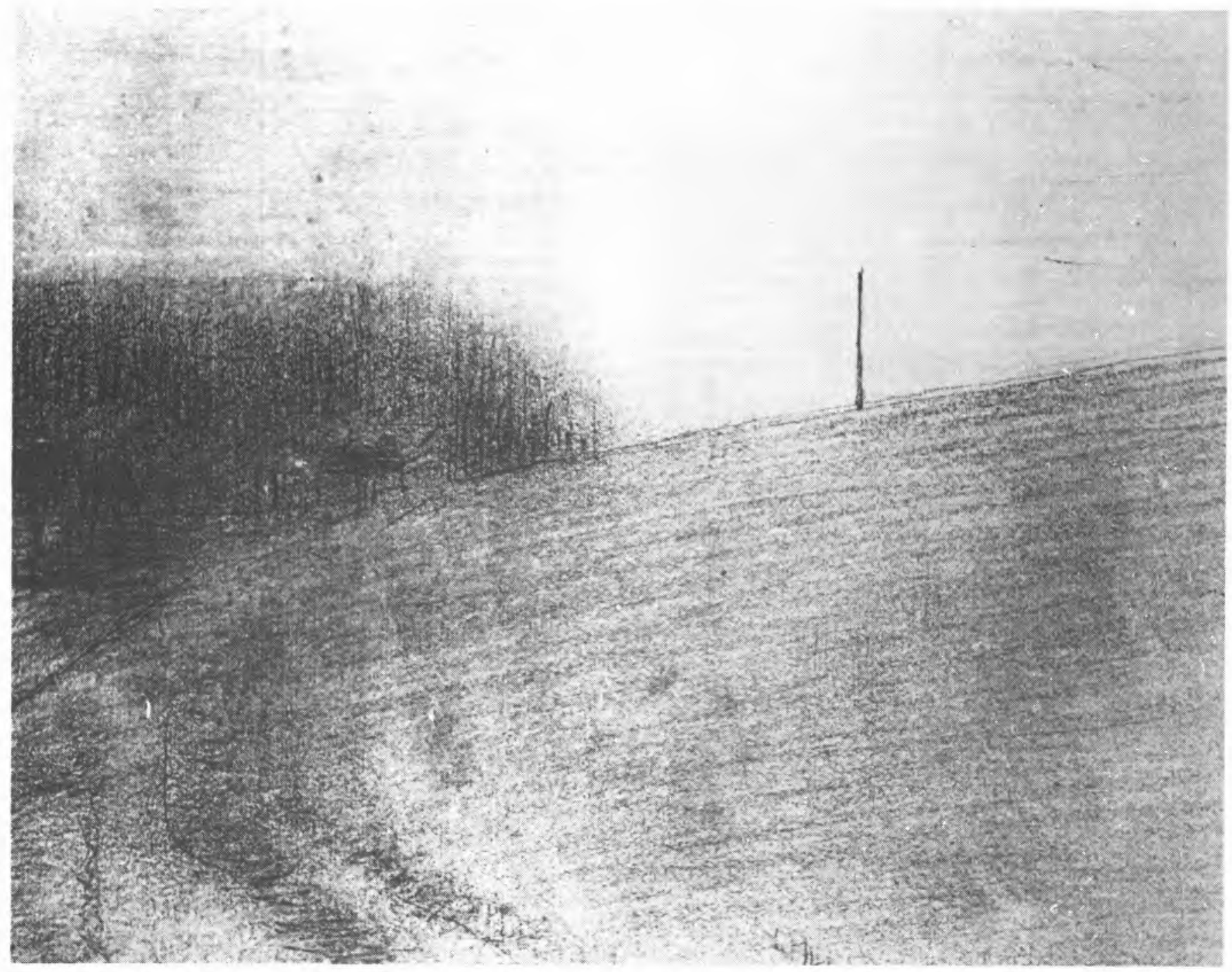

Seurat, Relvado, desenho, c. 1882

dém pela própria fotografia - achava que a sua «descoberta" e o seu desenvolvimento eram tão esperados e óbvios que lhe deveria ocupar o mínimo de tempo - e a combinação engenhosa de um matemático, um astrónomo e um químico, só justificam a credibilidade cega e desatenta, e a indecisão futuras do nosso relacionamento escalar com a fotografia, do micro ao macro-universo. A pulga (1860) e o eclipse do Sol (1861) de Parcic desestabilizaram definitivamente a nossa já insegura posição no Universo e a sua assimetria.

A gordura determinou ou acentuou as diferentes passagens da rudeza do desenho (ponto de aço) e da sua inacessibilidade (grafite britânica) para a sua definitiva agilidade e subtileza (lápis Conté); para a reprodução furiosa ou desenfreada e a confusão inquietante entre original manual e cópia (Senefelder); para a reprodução entre original real e cópia (Nièpce); em por enquanto finalmente, para a reversibilidade tonal, ou seja, para a tão rica convulsão entre cópias e perfeição, entre belo e sublime (Talbot/Herschel).

A gordura é escorregadia e lubrificante, ela coloca-se nos interstícios da realidade com que nos habituámos a conviver - será melhor dizer connomear. Os céus de Talbot, Manet e Seurat são distintos e, ao distinguirem-se, questionam o céu como modelo - será que a $1 .^{\text {a }}$ cópia é, sempre, uma cópia imperfeita da sua ausência?

5. Não é possível desenvolver e aprofundar aqui as contribuiçðes técnicas e as repercussðes estéticas posteriores da gordura no desenho e na fotografia. Limito-me a enumerar alguns processos onde intervếm: pigmentos e azeite, tintas de óleos, lápis de ceras, pastéis de óleo, tintas de esmalte, tinta e lápis litográfico, Calotipo/Papel Salgado, Heliografia, Platina e Palladium, óleo e Bromóleo, Processo Fizeau, Photogravure e Rotogravura de Klić, Colotipo de Poitevin, etc. - no Desenho, na Litografia, na Fotografia e na Fotocerâmica através de Luz.

Por espanto e coerência (correndo o risco de autodesilusão) acrescento a inutilidade daquilo que acabei de dizer. Tenho, por outro lado, a noção de que estou a fazer/dizer algo completamente desactualizado dentro de pouco tempo.

A fraqueza da constatação e da justificação verbal é um postulado da grandeza do "projecto intermediário" da realidade e da capacidade de a pensar.

Não tenho palavras para dizer. Mas terei dito?

\section{Uma biografia possivel para a GORDURA na fotogra- fia, no desenho e na luz.}

Nièpce, Isidore, Histoire de la Découverte improprement nommée daguerréotypie, Astier, Paris, 1841

Jay, Paul, Nièpce, premiers outils, premiers résultats, Musée Nicéphore Nièpce, Chalon-sur-Saône, 1978.

Nièpce, Joseph Nicéphore, Correspondances 1825-1829, Pavillon de la Photographie, Rouen, 1973.

Buckland, Gail, Fox Talbot/The Invention of Photography, Godine, New York, 1980. 
Talbot, William H. Fox, The Pencil of Nature, Da Capo, New York, 1969 (reedição do original de 1844).

Gernsheim, Helmut, The Origins of Photography, Thames and Hudson, London, 1982.

Newhall, Beaumont, Latent Image, University of New Mexico, 1983. Crawford, William, The Keepers of Light, Morgan \& Morgan, New York, 1979.

Gilardi, Ando, Creatività e informazione fotografica, in Grafica e Imagine, Einaudi, Torino, 1980.

Pirenne, H., Optics, Painting and Photography. Cambridge University Press, London, 1970.

Mella, Federico Arborio, Sulla Strada della Fotografia, Feltrinelli, Milano, 1976.

Watrous, James, The Craft of Old Master Drawings, Wisconsin Press, Madison, 1957.

Marks, Claude, From the Sketchbooks of the Great Artists, Hart-Davis, London, 1972.

Mendelowitz, Daniel M., Drawing, Holt, Rinehart and Winston, New York, 1967.

"On Drawing an Object». Richard Wollheim, 1965, in Aesthetics, edited by Harold Osborne, Oxford Univ., London, 1972.

Rose, Bernice, Drawing Now, Museum of Modern Art, New York, 1976.

Hullmandel, C., The Art of Drawing on Stone, London, 1824.

Senefelder, Alois, A Complete Course in Lithography, London, 1819.
Brunner, Felix, A Handbook of Graphic Reproduction Processes, Arthur Niggli Teufenn, Suiça, 1962.

Ivins, William M., Notes on Prints, MIT Press, New York, 1969. Ivins, William M., How Prints Look, Museum of Modern Art, New York, 1943.

Ivins, William M., Image impresa y conocimiento, Gustavo Gili, Barcelona, 1975.

Jussim, Estelle, Visual Communication and the Graphic Arts, Browker Comp., New York, 1983.

"L'Oeuvre d'Art a L'Ėre de sa reproductivité Technique», Walter Benjamin, in L'Homme, le langage et la Culture, Gonthier, Paris. Boas, Franz, Primitive Art, reed. Dover, New York.

Panofsky, Erwin, IDEA, reed. francesa Gallimard, 1983.

Wittgenstein, Ludwig, Blue and Brown Books, Oxford University Press, London, 1958.

Kubler, George, The Shape of Time, Yale University Press, 1962. Leroi-Gourhan, André, O Gesto e a Palavra, 2 - Memórias e ritmos, ed. port. Ediçðes 70, Lisboa, 1983.

Maitte, Bernard, La Lumière, Seuil, Paris, 1981.

Broglie, Louis de, Matière et Lumière, Albin Michel, Paris, 1937. Lewkowitsch, J., The Chemical Technology of Oils, Fats and Waxes (3 vols) MacMillan, London, 1922-38.

Brusatin, Manlio, Histoire des Couleurs, ed. Flammarion, Paris, 1986 (1983).

\title{
DINAMISMO - QUALIDADE
}

\author{
SERVIÇO
}

\section{ESCOLHA - EFICIÊNCIA}

PEÇA-NOS A LISTA DAS NOSSAS REPRESENTADAS

ALGUMA LHE INTERESSARÁ!

Estamos à distância do seu telefone...

QUINTA DA PIEDADE, LOTE $12 \cdot 1 .^{\circ}$ 